\title{
A propósito da cartovideografia sociocultural Lá do Leste
}

Claudia Turra Magni ${ }^{1}$

CAFFÉ, Carolina; HIKIJI, Rose Satiko Gitirana. Lá do Leste [livro eletrônico]: uma etnografia audiovisual compartilhada. São Paulo: Humanitas, 2013. 68 p. 3072 Kb ; PDF

CAFFÉ, Carolina; HIKIJI, Rose Satiko Gitirana, DANTAS, Paulo. Lá do Leste. [vídeo]. Direção, pesquisa e roteiro de Carolina Caffé e Rose Satiko Gitirana Hikiji. Produção de Paulo Dantas. São Paulo, Etnodoc, 2010. 1 DVD, 28 min, NTSC, cor.

CAFFÉ, Carolina; HIKIJI, Rose Satiko Gitirana. A arte e a Rua. [vídeo]. Direção, pesquisa, roteiro e produção de Carolina Caffé e Rose Satiko Gitirana Hikiji. São Paulo, LISA-USP, Instituto Pólis e W.S. Produções, 2011. 1DVD, 44 min., NTSC, cor.

Site Lá do Leste:

Disponível em: http://www.ladoleste.org/ Acesso em: 31 jul 2014.

Site do Mapa das Artes de Cidade Tiradentes:

Disponível em: http://www.cidadetiradentes.org.br Acesso em: 31 jul 2014.

1 Professora da Universidade Federal de Pelotas (Bacharelado e PPG em Antropologia), Pelotas, Rio Grande do Sul, Brasil. Doutora em Antropologia pela École des Hautes Etudes en Sciences Sociales (França), coordenadora do Laboratório de Ensino, Pesquisa e Produção em Antropologia da Imagem e do Som/ICH/UFPel. E-mail: clauturra@yahoo.com.br. 
A arte, você produz pra se sentir melhor!

Daniel Hylárioº

Criada nos anos 1980, na periferia leste de São Paulo, Cidade Tiradentes foi o destino de famílias de baixa renda removidas dos bairros centrais da cidade, destinados à especulação imobiliária. À época, a arte não integrava as temáticas privilegiadas pelas Ciências Sociais brasileiras, mais atentas aos modos de produção e conflitos de classes. Atualmente, quando aquele Distrito de $250 \mathrm{mil}$ habitantes tornou-se o maior conjunto habitacional popular latino-americano, as formas de expressão, produção e consumo artísticos de seus moradores passam a ganhar relevância geopolítica e epistemológica, na medida em que os mecanismos estratégicos na formação e transformação de territórios são percebidos como constitutivos da luta por cidadania e das disputas internas entre coletivos humanos.

É nesse contexto que, a partir de 2009, durante quatro anos de pesquisa, foi realizada a Cartovideografia Sociocultural da Cidade Tiradentes, sob coordenação das documentaristas Carolina Caffé, cientista social, e Rose Satiko Hikiji, antropóloga. Um site interativo com o Mapa das Artes de Cidade Tiradentes (www.cidadetiradentes.org.br) e o site Lá do Leste: uma etnografia audiovisual compartilhada, (www.ladoleste.org/), com dois filmes, um livro e extras (também disponíveis em versão física), dão dimensão da amplitude do projeto. Trata-se de uma obra profusa, complexa, sui generis, cujos fundamentos teórico-metodológicos e implicações epistemológicas, sociais, políticas e culturais merecem especial atenção.

Comecemos pelo site interativo com a cartografia das artes de Cidade Tiradentes, o primeiro produto do projeto, realizado por uma equipe do Instituto Pólis, com auxílio de quatro agentes culturais locais e apoio do Centro Cultural da Espanha em São Paulo. Sobre um mapa físico e geográfico (nas versões mapa, satélite, híbrido, estilizado e por setores), é possível identificar, por exemplo, informações sobre diversos "Espaços" (Públicos, ONGs, Outros) e "Linguagens": Dança, Música, Teatro, Literatura, Audio Visual, Artes Plásticas. Também flutuam sobre o mapa, algumas tags, como "Mulher", "Negro", "Deslocamento", "Luta”, "Cartovideografia", "Arte + Rua", "FunkCT", "Juventude", "Economia da Cultura", "Poder Público", etc. A respeito destes temas do cotidiano das

2 Ativista cultural, morador de Cidades Tiradentes, produtor local e narrador do filme A Arte e a Rua. 
comunidades ou daqueles espaços e expressões artísticas, o navegador encontra múltiplas referências textuais, fotográficas, musicais, links e clipes. Parte deste material, recolhido, produzido e editado inicialmente pelos pesquisadores-moradores junto aos artistas locais, passou a ser alimentado pelos próprios membros das comunidades, através de cadastramento e postagem de seus dados, ou então pela participação no Fórum existente no site, que fomenta a comunicação, potencializando redes culturais, sejam internas ou amplificadas, rompendo uma possível guetificação daquele Distrito periférico da Grande São Paulo.

Assim, este mapeamento de práticas artísticas da Cidade Tiradentes não almeja cristalizar localizações a partir de uma mirada macroscópica, externa e distante àquele universo, mas, nos termos do antropólogo urbano José Guilherme Magnani³, é realizado numa perspectiva "de perto e de dentro", em que pesquisadores e nativos participam do mesmo plano, dos mesmos processos cognitivos, acompanhando as dinâmicas e as práticas dos atores sociais. Em vez de distanciamento e neutralidade na relação entre pesquisador e pesquisado, tem-se, na verdade, a ruptura das fronteiras epistemológicas e dissolução das categorias que separariam sujeito e objeto na produção do conhecimento, com aposta no processo interventivo, na implicação de ambos, que se transformam mutuamente, junto com o fluxo da pesquisa, da Cidade e da vida. Avessa à objetivação de registros incontestes e pretensas verdades conclusivas, a proposta deste projeto cartovideográfico é, antes, guiada por afecções, motivada por subjetividades e desenvolvida por processos de conhecimento compartilhados, virtualmente infinitos. Estruturado por fragmentos de múltiplas autorias, o site apresenta-se como uma obra aberta, orquestrada pelo princípio da montagem - técnica magistralmente desenvolvida por Walter Benjamin na Obra das Passagens ${ }^{4}$ - permitindo ao navegador/leitor inserir-se no projeto, interpretá-lo e reinventá-lo constantemente.

Da mesma forma que a construção participativa é empregada através dos recursos tecnológicos virtuais da WEB, os dois filmes ${ }^{5}$ Lá do Leste e A Arte e a Rua - que integram o projeto, apresentam-se

3 MAGNANI, José Guilherme Cantor. De perto e de dentro: notas para uma etnografia urbana. Revista Brasileira de Ciências Sociais. São Paulo, ANPOCS/Edusc, v. 17, n. 49, p. 11-29, 2002. DOI: http://dx.doi.org/10.1590/s0102-69092002000200002

4 Apud BOLLE, Willi. Fisiognomia da Metrópole Moderna: representações da história em Walter Benjamin. São Paulo: Editora da Universidade de São Paulo, 2000.

5 Acessíveis em http://www.vimeo.com/lisausp/ladoleste e http://vimeo.com/ lisausp/aarteearua. Aprovado, em 2010, pelo Edital do Etnodoc - Edital de Apoio a Documentários Etnográficos sobre Patrimônio Imaterial (IPHAN), o curtametragem Lá do Leste deu origem ao média-metragem, A Arte e a Rua, finalizado em 2011 junto ao (LISA-USP) e ao Instituto Pólis. 
como produtos polifônicos, inspirados na proposta ética e estética do antropólogo-cineasta Jean Rouch. Entusiasmado, na sua infância, pelo filme Nanook of the North, cujo sucesso deveu-se, em grande parte, à convivência e familiaridade do realizador, Robert Flaherty, com os inuit, Rouch também adotou a imersão e partilha com o grupo estudado como procedimento central do método etnográfico, tendo realizado cerca de 80 filmes com seus parceiros africanos, entre 1947 e 2003, ano do seu falecimento. Prenunciando a crítica da Antropologia Pós-Moderna à autoridade do etnógrafo, único protagonista do discurso científico, o cineasta procurou "passar a palavra" aos nativos, associando-se a eles em projetos fílmicos compartilhados, movidos pelo desejo e pela aventura coletiva. Sem enquadrar o outro em categorias e identidades estanques, adequadas às pré-concepções do pesquisador, o projeto rouchiano move-se pela partilha e fabricação de sonhos, capazes de transformar existências, mobilizar e contribuir para a organização e reterritorialização de indivíduos e coletividades. Em meio às adversidades das condições objetivas advindas do lugar que ocupam no modo de produção, a ficcionalização impõe-se como meio de desvelar a realidade.

Em Cidade Tiradentes, como em qualquer outra parte do mundo, a imaginação, a expressão simbólica, a produção e o acesso à cultura e à arte são elementos vitais que permitem às pessoas "se sentirem melhor", como diz Daniel Hylário, o ativista cultural citado no prólogo desta resenha. Junto com outros moradores da Cidade Tiradentes, eles protagonizam os filmes e participam do agenciamento da pesquisa, que, partindo de algumas histórias de vida, entrelaçam narrativas sobre a criação e transformação do Distrito e das artes de rua que nele se gestaram, com destaque para quatro coletivos: 5Zonas (graffiti), RDM Rapaziada Do Morro (grupo de rap), B-Boys do Tiradentes (street dancers) e Relato Final (grupo de rap gospel).

Ao traçar um paralelo entre arquitetura e narratividade, Paul Ricoeur $^{6}$ demonstra como ambas são afeitas à interpretação. Edificada no espaço, a arquitetura se constrói na pedra, enquanto a narratividade transcorre no tempo, inscrevendo-se na linguagem. Propondo não só um paralelo, mas um cruzamento entre estas configurações, o filósofo argumenta pela necessidade de releitura atenta ao ambiente urbano, aos nossos lugares de vida, a partir da reflexão sobre nossa maneira de habitar - um habitar receptivo e ativo, capaz de promover uma interpretação plural de nossas

6 RICOEUR, Paul. Arquitetura e Narratividade. Urbanisme, n.zo3, nov/dez., p. 44-51, 1998. 
sociedades, baseada em um trabalho de memória que não implique em repetição obsessiva, mas em reconstrução.

Michel De Certeau ${ }^{7}$ também relaciona estruturas narrativas com sintaxes espaciais. Para ele, os lugares, enquanto configurações instantâneas de posições, tem estabilidade, e, portanto, correspondem à palavra; enquanto os espaços, animados pelo conjunto de movimentos que nele se desdobram, são desprovidos de estabilidade e, assim, correspondem à fala. Para este autor, que sustenta a importância de se pesquisar o espaço a partir das ações que nele transcorrem, os relatos são, eles próprios, uma prática do espaço: as ações narrativas são formas elementares das práticas organizadoras do espaço.

Nas narrativas fílmicas aqui em questão, os moradores-artistas-ativistas- pesquisadores, em diálogo com os pesquisadores-forasteiros, constroem narrativas a partir de memórias pessoais e coletivas, jamais consensuais, que transformam lugares cartesianos em espaços existenciais, repletos de sentidos e interpretações. Na concepção dos filmes a que nos atemos, as metodologias adotadas foram especialmente exitosas: do cinema de observação, em que a câmera registra sem intervir, ao cinema participativo, em que a câmera agencia e desencadeia performances, envolvendo-se com o cotidiano da comunidade, deslocando-se por diversos territórios e acompanhando manifestações artísticas diversas, temos uma gama de situações e contextos que colocam em evidência distintas maneiras de narrar e habitar a Cidade Tiradentes. Elas correspondem a complexas e, por vezes conflituosas, práticas dos espaços, com seus respectivos modos de apropriação, flanagem e fruição de territórios. Paralelamente, foi empregado o método da câmera-bastão, que permitiu aos atores sociais se alternarem no registro de situações vivenciadas dentro e fora do Distrito (no trajeto e decorrer do trabalho, em situações de intimidade familiar, dentre outras), sem a presença da equipe externa. Por fim, as narrativas poéticas, integram-se às demais metodologias fílmicas, fazendo eco à temática artística do projeto de pesquisa-intervenção, através do recurso ao stop motion na edição de uma sessão de grafitagem do coletivo 5Zonas, e de um videoclipe com o grupo de rap RDM, também disponíveis nos extras do DVD.

Vem completar estas narrativas imagéticas e sonoras apresentadas em diferentes mídias, o livro Lá do Leste: uma etnografia audiovisual compartilhada, construído pela transcrição de "cenas" e "bastidores" das gravações fílmicas. Nos termos das coordenadoras do projeto,

7 DE CERTEAU, Michel. A invenção do cotidiano: artes de fazer. Petrópolis: Vozes, 1994. 
trata-se de um "roteiro às avessas", cuja edição assemelha-se ao método cinematográfico de montagem. Isso nos remete novamente a Benjamin, para quem a técnica da montagem serve de base para a sua concepção historiográfica. No livro em questão, estes depoimentos fragmentários e polifônicos articulam-se organicamente com fotos de paisagens e da arquitetura local, de práticas cotidianas, espaços de vida, momentos de sociabilidade e trabalho, deslocamento e repouso, práticas e expressões artísticas, cenários domésticos, corpos e seus assessórios, em planos gerais ou detalhes flagrantes.

Disponível em versão física, em que o livro vem acompanhado do DVD, o conjunto de todos estes produtos também é acessível pelo site Lá do Leste (www.ladoleste.org), cujo design claro, dinâmico e poético apresenta-se em plena coerência conceitual com o projeto. Sem buscar uma explicação linear e unívoca da realidade, construída assepticamente "sobre" o outro, por agentes externos, que se outorgariam o status de tradutores culturais, o livro, assim como o projeto cartovidegráfico mais amplo, investe em formas de saber "com" os habitantes de Cidades Tiradentes $^{8}$. Ao proceder por bricolagem, combinação, superposição, contraste ou choque de "imagens dialéticas", construídas por múltiplos olhares, posições e narrativas não hierarquizados, propicia-se, em termos benjaminianos, um "despertar da conhecibilidade". Compartilhados, estes saberes fomentam e potencializam a rede de artistas e suas artes. Afinal, sem elas, como nos sentiríamos?

DOI: http://dx.doi.org/10.11606/issn.2316-901X.v0i59p405-410

8 No verbete "cartografar", lè-se: "Aqui, pesquisar não tem mais a ver com saber sobre, pois se trata de saber com.” FONSECA, Tânia Mara Galli; NASCIMENTO, Maria Lívia do; MARASCHIN, Cleci. Pesquisar na diferença: um abecedário. Porto Alegre, Sulina, 2012, p. 45 . 